\title{
TEKNIK PENANGKAPAN UDANG GALAH (Macrobrachium rosenbergii) DI PERAIRAN SUNGAI MUSI BA GIAN HILIR SUM-SEL
}

\author{
Syamsul Bahri") \\ *)Teknisi Litkayasa pada Balai Riset Perikanan Perairan Umum, Palembang
}

\section{PENDAHULUAN}

Berdasarkan karakteristik limnologi Sungai Musi dibagi 3 bagian besar yaitu DAS bagian hulu, tengah, dan hilir (Samuel et al., 2002). Kegiatan penangkapan udang galah terdapat di wilayah Sungai Musi bagian hilir mulai dari Desa
Tebing Abang bagian hilir hingga ke muara Selat Bangka dekat Desa Sungsang berada pada ketinggian antara 0-15 $\mathrm{m}$ di atas permukaan air laut (Samuel et al., 2002). Daerah bagian hilir merupakan perairan yang banyak dipengaruhi perairan rawa banjiran dan pasang surutnya air laut (Gambar 1).

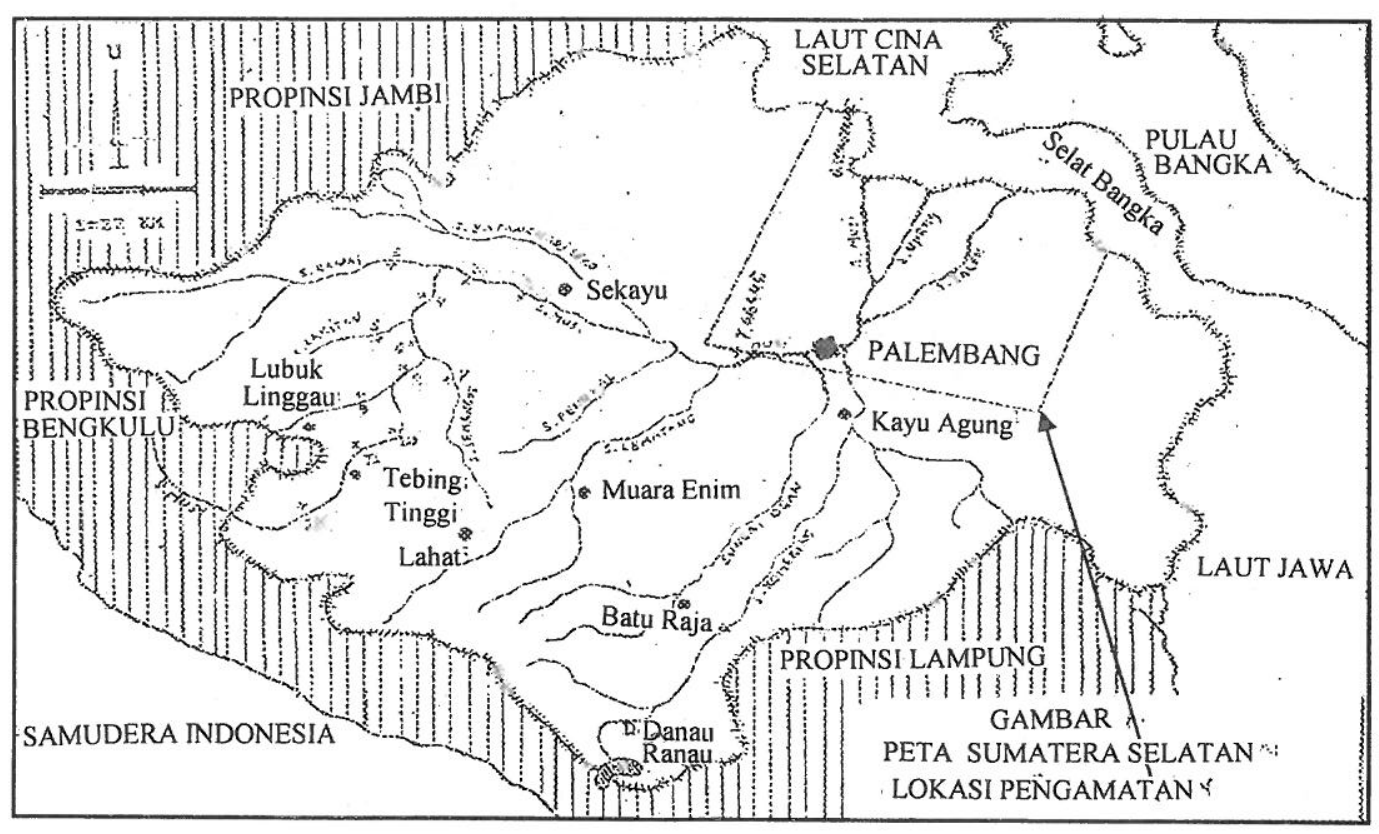

Gambar 1. Peta lokasi pengamatan penangkapan udang galah (Macrobrachium rosenbergii).

Udang galah (Macrobrachium rosenbergii) merupakan salah satu komoditas ekspor dan konsumsi yang penting di perairan air tawar. Udang tersebut termasuk dalam jenis Palaemonidae, yang sebagian besar hidup di air tawar, hanya pada saat penetasan telurnya yang sudah dibuahi menuju muara sungai yang berair payau. Udang melakukan pemijahan mencapai puncaknya pada musim penghujan (Desember dan Januari). Pemijahan udang galah berlangsung di perairan tawar yang jauh dari kuala sungai (Utomo et al., 1996).

Alat tangkap udang galah yang dioperasikan oleh nelayan masih tergolong alat tangkap tradisional seperti hampang, bengkirai bilah, bubu 
gendang, jala, tuguk, dan pancing. Tujuan tulisan adalah untuk mengetahui teknik penangkapan udang galah dengan alat tangkap hampang yang dipergunakan oleh nelayan di perairan Sungai Musi bagian hilir.

\section{POKOK BAHASAN}

\section{Bahan dan Alat}

Bahan yang dipergunakan untuk pembuatan hampang adalah: 1) waring net, 2) tali nilon, 3) benang penjahit, dan 4) kayu unjar/bambu.
Alat yang dipergunakan adalah: 1) gunting, 2) jarum, 3) pisau, dan 4) sarana pendukung serok udang.

\section{CARA PEMBUATAN}

Tali tambang/nilon sebagai tali ris alat tangkap hampang, tali ris atas dan bawah disatukan dengan waring net dijahit pada tali ris tersebut, baik yang bagian atas maupun yang bagian bawah sehingga membentuk empat persegi panjang (Gambar 2).

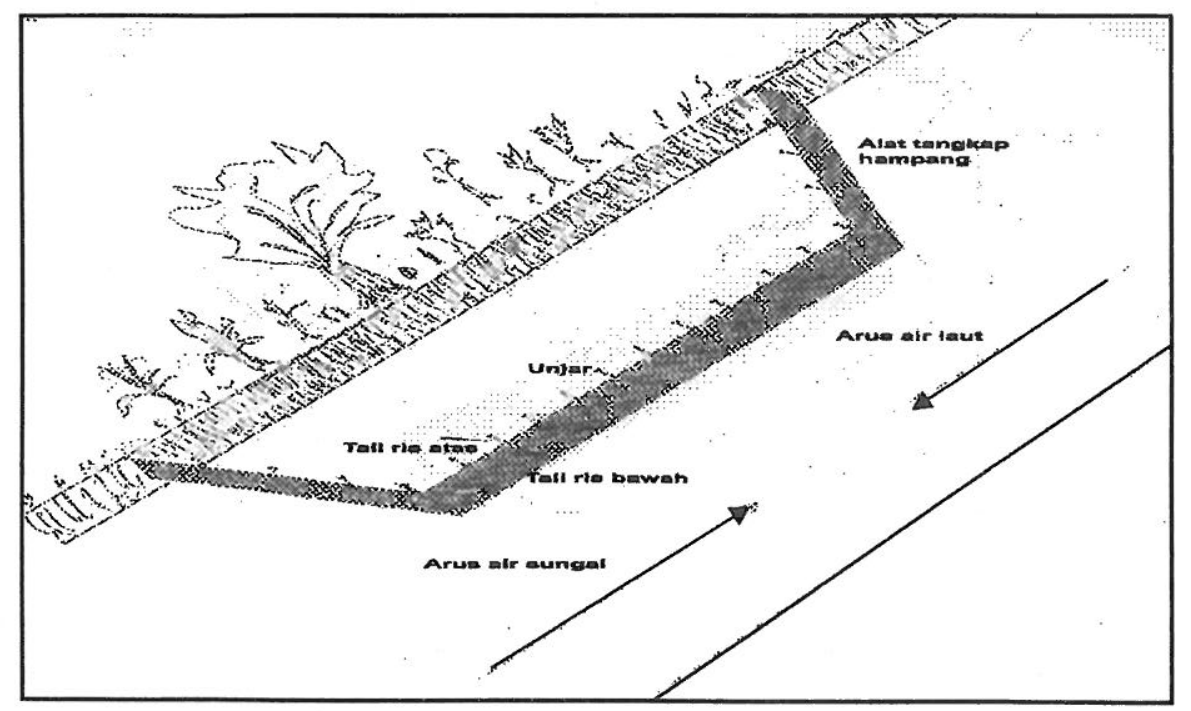

Gambar 2. Alat Tangkap Hampang.

\section{Cara Pengoperasian}

1. Alat tangkap hampang dipasang di pantai \pm 4 $6 \mathrm{~m}$ dari tepi sungai dengan membujur sehingga membentuk setengah lingkaran (Gambar 2).

2. Tali ris alat tangkap bagian bawah dimasukkan menancap ke dalam lumpur dan dijepit dengan kayu guna supaya alat tersebut tidak timbul pada permukaan air naik.

3. Kayu unjar dipasang sesuai dengan panjang alat dari bagian hulu sampai ke hilir, jarak antara unjar yang satu dengan lainnya $2 \mathrm{~m}$.

4. Tali ris atas dan bawah pada bagian ujung dan pangkal diikatkan pada unjar yang telah ditancapkan pada tepi sungai.
5. Alat tangkap dirapikan dan ditutup dengan lumpur, seolah-olah alat tersebut tidak ada didasar air sehingga udang yang akan mencari makan akan lewat di atas alat tersebut naik ke daratan sungai.

6. Sebelum arus air pasang kembali ke sungai, tali ris alat tangkap hampang bagian atas diangkat ke atas permukaan air dan diikatkan satu persatu pada kayu unjar yang sudah terpasang.

7. Udang yang tertangkap dalam alat tangkap hampang dapat diambil setelah air surut dengan kedalaman 30-50 cm, udang diserok dengan alat tangkap sanggi dan dimasukkan pada tempat penampungan. 
Tabel 1. Hasil tangkapan udang galah dalam satu bulan

\begin{tabular}{clccc}
\hline No. & & Ukuran udang (Panjang) & Jumlah (kg) & Keterangan \\
\hline 1. & Induk & $15-30 \mathrm{~cm}$ & 5.440 & Jumlah alat tangkap 68 unit \\
2. & Dewasa & $10-15 \mathrm{~cm}$ & 9.520 & \\
3. & Anak & $2-10 \mathrm{~cm}$ & 12.240 & \\
\hline Jumlah Total & & 27.200 & \\
\hline
\end{tabular}

Sumber: Data Primer Tahun 2003.

8. Hasil perolehan/tangkapan selanjutnya ditampung/dikumpulkan dalam tampungan udang berupa sangkar untuk yang masih hidup, bila yang sudah mati ditampung di dalam bak diberi es supaya mutu udang tetap baik.

\section{Aspek Penangkapan}

1. Alat tangkap hampang sangat baik dioperasikan di perairan sungai pasang surutnya air laut.

2. Pengoperasian alat dilakukan pada musim kemarau (surut) sampai awal musim penghujan (banjir).

3. Produktivitas alat ini di Sungai Musi bagian hilir berkisar antara 10-20 kg/1 alat/malam.

Di Sungai Musi bagian hilir dengan pengaruh fluktuasi air pasang surutnya air laut, udang yang tertangkap dengan alat tangkap hampang bermacam ukuran dari yang kecil sampai udang yang besar.

\section{KESIMPULAN}

1. Pengoperasian alat ini harus dilakukan secara hati-hati sebab alat ini dioperasikan di pantai, sungai dengan fluktuasinya pasang surut, gelombang besar, dan kencangnya angin dan sering turunnya hujan yang sangat lebat.
2. Alat ini berguna untuk menambah penghasilan keluarga petani/nelayan.

3. Perlu diwaspadai karena penangkapan memakai alat tangkap hampang bermacam ukuran udang tertangkap.

\section{DAFTAR PUSTAKA}

Samuel \& S. Adji. 1996. Beberapa aspek limnobiologi dan penangkapan di Daerah Aliran Sungai Musi bagian tengah-hulu, Sumatera Selatan. Prosiding Seminar Pengkomunikasian Hasil Penelitian Perikanan Perairan Umum di Sumatera Selatan. Lolitkanwar PalembangBalitbang Pertanian Departemen Pertanian No. 2 hal. 43-52.

Samuel et al., 2002 Inventarisasi dan distribusi kota serta karakteristik habitat perairan Sungai Musi. Laporan Teknis 2002, Proyek Penelitian Perikanan Air Tawar pada Balai Riset Perikanan Perairan Umum Palembang. 32 hal.

Utomo, A.D. Ondara, \& D.D. Hoggart. 1996. Pendugaan pertumbuhan udang galah (Macrobrachium rosenbergii) di Sungai Lempuing Sumatera Selatan. Prosiding Seminar Pengkomunikasian Hasil Penelitian Perikanan Perairan Umum di Sumatera Selatan. Lolitkanwar Palembang-Balitbang Pertanian Departemen Pertanian No. 2 hal. 6267. 